\title{
Calibrating a camera trap-based biased mark-recapture sampling design to survey the leopard population in the N’wanetsi concession, Kruger National Park, South Africa
}

\author{
Nakedi W. Maputla ${ }^{1,2 *}$, Christian T. Chimimba ${ }^{2,3}$ and Sam M. Ferreira ${ }^{4}$ \\ ${ }^{1}$ African Wildlife Foundation, AWF Conservation Centre, Ngong Road, Karen, P.O. Box 310, 00502, Nairobi, Kenya, ${ }^{2}$ Department of Zoology \& \\ Entomology, Mammal Research Institute (MRI), University of Pretoria, Private Bag X20, Hatfield, 0028, South Africa, ${ }^{3}$ Department of Zoology \\ and Entomology, DST-NRF Centre of Excellence for Invasion Biology (CIB), University of Pretoria, Private Bag X20, Hatfield, O028, South Africa \\ and ${ }^{4}$ Scientific Services, South African National Parks (SANPARKS), Skukuza, 1350, South Africa
}

\section{Abstract}

Estimating large carnivore abundance can be challenging. A biased leopard (Panthera pardus) population survey was conducted in the N'wanetsi concession in the Kruger National Park (KNP), South Africa, using motion-sensitive camera traps from April to August 2008. Survey effort included 88 trapping occasions and 586 trap days. The survey yielded 24 leopard photographs, comprising fourteen adults of eleven males and three females. The capture rate was determined to be 24.4 trap days per leopard. Estimates of population abundance stabilized at approximately 500 trap days. Precision of population estimates began to stabilize after 378 trap days. We estimated that there were nineteen leopards in an area of $150 \mathrm{~km}^{2}$. Leopard density was estimated at 12.7 leopards per $100 \mathrm{~km}^{2}$. We explore the possibility of employing the methods used in this study to survey the leopard population in the KNP and surrounding areas.

Key words: camera trap, effort, Kruger National Park, Leopard, Panthera pardus, population estimate, South Africa

\section{Résumé}

Il peut Átre difficile d'estimer l'abondance de grands carnivores. Une étude biaisée d'une population de léopards (Panthera pardus) fut menée dans la concession N'wanetsi du Parc National Kruger, en Afrique du Sud, en utilisant des pièges photographiques détecteurs de mouvement entre avril et août 2008. Cette étude compte 88 occasions

*Correspondence: E-mail: nmaputla@zoology.up.ac.za de piégeage sur 586 jours de piégeage. Elle a récolté 24 photos de léopards dont 14 adultes, 11 mâles et 3 femelles. Le taux de capture déterminé est de 24,4 pièges-jours par léopard. Les estimations de la population se sont stabilisées approximativement à 500 pièges-jour. La précision des estimations de population a commencé à se stabiliser après 378 pièges-jour. Nous avons estimé qu'il y avait 19 léopards sur une superficie de $150 \mathrm{~km}^{2}$. La densité des léopards a donc été estimée à $12,7 / 100 \mathrm{~km}^{2}$. Nous étudions la possibilité d'employer les méthodes utilisées dans cette étude pour étudier la population de léopards du KNP et des zones voisines.

\section{Introduction}

Estimating population abundances for solitary and secretive carnivore species with extensive home ranges poses challenges caused by sampling design and the suitability of methods (Karanth \& Nichols, 2000). Indirect methods use cues such as kills and scats (Karanth \& Sunquist, 1995; Marker, Mills \& Macdonald, 2003; Ott, Kerley \& Boshoff, 2006; Owen-Smith \& Mills, 2008), habitat assessments (Daly et al., 2005), prey availability (Bailey, 1993; Carbone \& Gittleman, 2002) and pug marks (Stephens et al., 2006). Sometimes researchers conduct interviews with local people to carry out inventories (Tobler et al., 2008). However, such indices carry assumptions about the relationship between population size of a species and index values related to species local population structure.

Direct methods use formal survey designs, such as callup stations where a recording of a prey species, such as a buffalo calf in distress, is played repeatedly to attract large 
carnivores (Mills, Juritz \& Zucchini, 2001; Ferreira \& Funston, 2010) or mark-recapture techniques (Karanth \& Nichols, 1998; Balme, Hunter \& Slotow, 2009). Data collected using these methods may be good for population monitoring, given enough time and resources (Harris, 1986), but often these are found to be unreliable (Tobler et al., 2008). For species with natural markings, the use of camera traps may provide valuable options to address such challenges, and in some instances, natural markings may not even be necessary to establish animal abundance from photographs (Rowcliffe et al., 2008). The use of camera traps may be particularly suitable for surveying secretive carnivores for which cues are hard to find (Karanth \& Nichols, 2000). Estimating leopard (Panthera pardus) abundance epitomizes these challenges.

Passive detection of individually recognizable animals through camera traps allows the use of mark-recapture techniques to estimate population abundance (Nichols, 1992; Kauffmann et al., 1997; Efford, Dawson \& Robbins, 2004). Abundance can be estimated with a narrow margin of error if the detection probability is high and camera shyness is low (Wegge, Pokheral \& Jnawali, 2004). Such camera trap-based mark-recapture studies have been used to estimate tiger numbers in Asia (Karanth \& Nichols, 1998), defined carnivore communities in Namibia (Kauffmann et al., 1997; Stein, Fuller \& Marker, 2008) and provided cheetah and leopard population estimates in South Africa (Marnewick, Funston \& Karanth, 2008; Balme, Hunter \& Slotow, 2009; Balme, Slotow \& Hunter, 2010a; Balme et al., 2010b). In addition, they have been used in short- and long-term population monitoring (Karanth et al., 2006) and in determining the ecological and temporal partitioning of large carnivores (RomeroMuñoz et al., 2010). Studies by Wang \& Macdonald (2009) and Sharma \& Jhala (2011) also included explicit evaluation of sampling effort to obtain statistically robust leopard population estimates.

Nevertheless, camera trap-based mark-recapture approaches are seldom used following standardized methods, thus often overlooking camera performance and efficiency (Kelly, 2008). This may result in varying surveying efforts (Henschel \& Ray, 2003) that may arise because of the duration of camera deployment. This may be caused by site-specific characteristics that may make standardization of methods inapplicable across a large geographical space with varying landscape features (White et al., 1978; Harris, 1986; Agresti, 1994; Kéry \& Schmidt, 2003; Efford, Dawson \& Robbins, 2004). Researchers thus need to accommodate changes across time and space to account for variability when conducting this type of work.

Estimating population size with acceptable accuracy and precision is a key challenge for field ecologists (Harris, 1986; Mills, Juritz \& Zucchini, 2001). Attaining precision is mainly affected by incomplete detection (White et al., 1978; Aebischer, 1986; Thompson, 2002), trapping design (Nichols, 1992) and effort (Karanth \& Nichols, 2000). For secretive carnivores such as leopards, researchers can use biased sampling anticipating the likely activity hotspots (Karanth \& Nichols, 1998), attractant sampling such as luring individuals to a trapping site (Henschel \& Ray, 2003), systematic sampling (Wegge, Pokheral \& Jnawali, 2004; Kauffmann et al. 1997) and complete random sampling (Maffei, Cuéllar \& Noss, 2004), or combinations of these. Several authors favoured biased sampling (Karanth \& Nichols, 1998; Jackson et al., 2006; Marnewick, Funston \& Karanth, 2008), but seldom checked the sampling effort to obtain the estimates with robust precision. This carries some value, because the detection of trends is dependent on precision of estimates (Harris, 1986), but effort has cost and efficiency implications.

In this study, we assessed these trade-offs using biased sampling of leopards as a case study. We aimed to assess the efficiency of cameras placed in a biased sample design to estimate the leopard population sizes by (i) defining how individual leopard trapping success varied with time; (ii) determining the effort to achieve an asymptote in new individuals captured; (iii) identifying the effort at which precision of population estimates stabilize; and (iv) establishing the abundance of leopards in the study area. We explore the possibility of employing a similar design to survey and estimate the leopard abundances in different landscapes of the KNP.

\section{Materials and methods}

\section{Study area}

The study was carried out at the N'wanetsi concession, which covers 15,000 ha in the south-central part of South Africa's KNP on the border with Mozambique (S24 24.2833 E31 $1^{\circ} 55.6833$; Fig. 1). The study area is in the subtropical semi-arid zone aligning with the Lebombo Mountains and has a mean annual rainfall of $514.6 \mathrm{~mm}$ (Gertenbach, 1980). There are marked differences in temperature between seasons with temperatures exceeding $40^{\circ} \mathrm{C}$ in the summer and as low as $0.2^{\circ} \mathrm{C}$ during winter. 


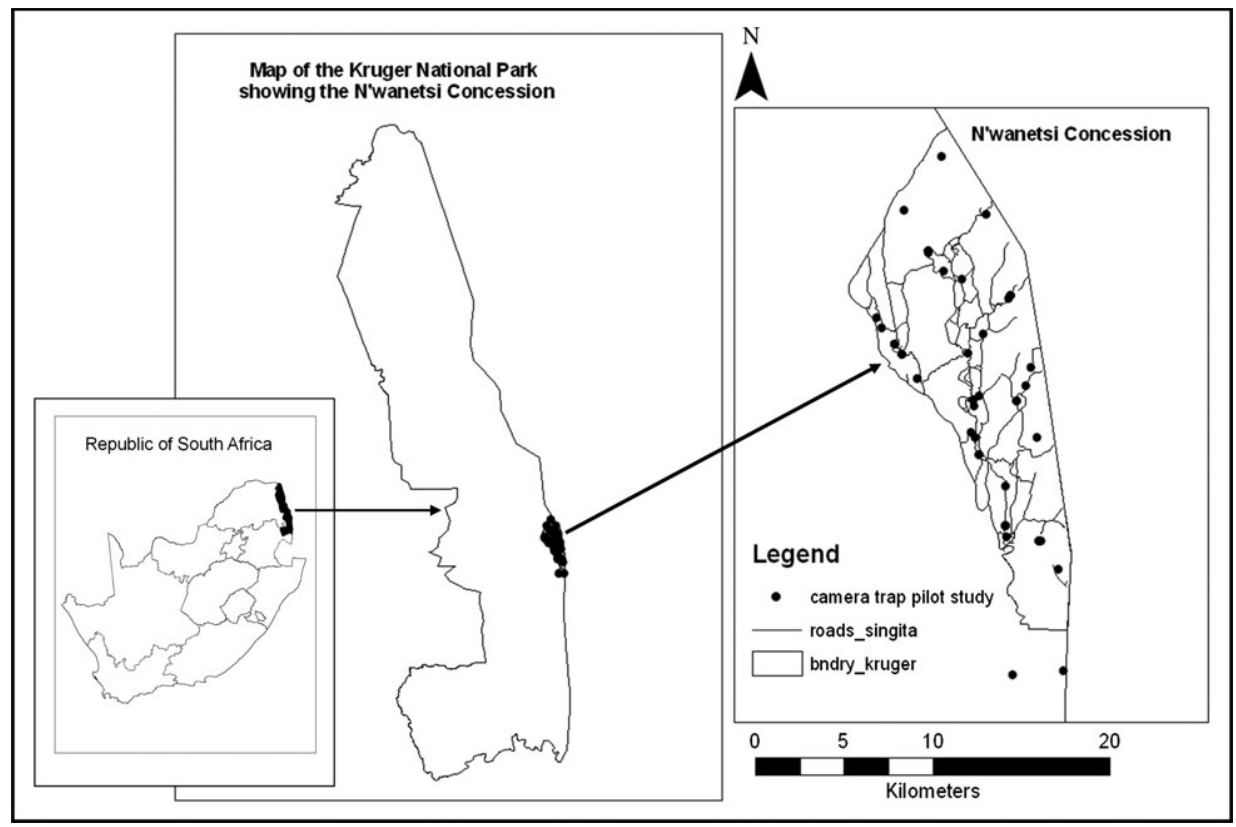

Fig 1 Map of South Africa (inset) and the Kruger National Park and the N'wanetsi concession, the study area

Two ephemeral rivers, the N'wanetsi and the Sweni, dissect the concession. The most dominant vegetation types are Acacia-Sclerocarya savanna woodland in the west of the Lebombo Mountains and the mixed Combretum woodland in the east, as well as in the mountains (Gertenbach, 1983).

\section{Data collection}

We used a biased sampling design (see Karanth \& Nichols, 1998) and placed nine Cuddeback ${ }^{\circledR}$ EXcite $^{\text {TM }}$ C2000 digital cameras and one Reconyx ${ }^{\mathrm{TM}}$ RM 45 camera in areas of known leopard activity based on the advice of the N'wanetsi concession's guides, game trails leading towards water points, drainage lines and ridges in the Lebombo Mountains provided focal points. An infra-red transmitter triggered a camera if the beam was broken by a moving object. Cameras also recorded times and dates when photographs were taken. A 1-min delay period between photographs was imposed on each camera to counter the effects of large herds of animals moving in the area. We placed the cameras between three and seven kilometres apart during each session in close proximity to roads for logistical reasons. The cameras captured leopard images over four sessions between April and August 2008 (Fig. 1). For each sampling session (22 days of 24-h length), some traps were shifted to accommodate for some logistical constraints. However, traps covered the same study area in a similar biased sample design, that is, traps were placed in areas of either known or expected leopard activity. We pooled camera-trapping sessions to give a total of 88 camera-trapping occasions.

To protect cameras from animals such as elephants, rhinos and Hyaenas, we placed them inside steel casings, made to fit the cameras. Casings were fixed to drop poles and lodged firmly in the ground. We also sprayed the casings with pepper spray to further protect them from being uprooted by either elephants or rhinos. We did not have inclinations to believe that pepper spray would affect leopard activity around the traps as the cameras were not placed in a way that would interfere with animal movements. Elsewhere (unpublished data by NWM), an even stronger agent, Capsicum concentrate, was used, and observations suggest that leopards were not affected. To upload images onto a laptop computer, we visited camera stations any day after the third day of either being placed or being checked.

Cameras that malfunctioned were excluded from the survey, but their data up to the day of malfunction were used. To overcome the inevitable inconsistencies caused by periods of not trapping in between surveys and camera malfunctions, each camera was allocated to a trap day. A trap day was defined as a camera active for a 24 -h period. 
Eleven events of camera malfunctions caused by power failure, animal interference and fire occurred after 52 occasions resulting in a loss of 384 trap days. Our data thus comprised 586 trap days.

\section{Data analysis}

Individual leopard identification. After uploading leopard images, we used the unique spot patterns on the flanks, legs and face to identify and allocate an identity number to each individual leopard. For this study, we used only one camera per station, which meant only one flank at a time was captured. To compensate for this discrepancy, we used images provided by visitors and guides at the N'wanetsi concession to verify the identity of each individual leopard. In cases where there were no supplementary images, we used only the right flank to identify individuals because $90 \%$ of the images were on the right flanks. Captures and noncaptures were recorded as either 1 or 0 , respectively, to create a camera capture history for each leopard in the form of a matrix. The matrix was imported into program CAPTURE (White et al., 1978; Rextad \& Burnham, 1991) for analysis.

Cumulative new leopard individuals and capture rates. To define how individual trapping success varied with time, we plotted the cumulative number of captures against time. The capture rate was calculated by dividing the increase in effort, which refers to the number of trap days, by the number of leopard images captured during the survey period. In addition, we ran 100 simulations that re-arranged capture events for all the captures to explore the stabilization of capturing new leopard individuals with increasing effort.

We used the generalized accumulation curve $\left(y=a x^{b}\right)$ to evaluate how leopard numbers increased as more individuals were captured (Flather, 1996). Desirable effort was achieved when the number of new leopards increased by less than $10 \%$ per unit increase in effort (Thompson et al., 2003; Wegge, Pokheral \& Jnawali, 2004).

To evaluate whether we observed all the leopards in the study site, we plotted the number of leopards versus the number of individuals as more captures were recorded during the survey. To account for individuals that we may have missed during the survey, we used Estimate S 8.2.0. (Colwell, 2006) to (i) generate data using jackknife and bootstrap methods; (ii) generate abundance-based coverage estimator (ACE; Chazdon et al., 1998), which uses information based on individuals that were captured on either ten or less occasions, and incidence-based coverage estimator (ICE; Chazdon et al., 1998), which uses information on leopards that were captured in ten or less camera trap stations (Lee \& Chao, 1994); and (iii) fit the Michaelis-Menten equation (MM; Colwell \& Coddington, 1994) based on the Mao Tau's curve for Lobs to predict the number of leopards where the curve levelled off.

Population estimates and precision. We used the program CAPTURE to estimate leopard abundance. CAPTURE uses mark-recapture methods to estimate population densities and abundance, by testing for population closure and assuming that all animals have equal opportunity of being captured. There were no observed either deaths or introductions during the survey, so we assumed that the population was closed (Otis et al., 1978). Furthermore, CAPTURE has several models that account for the variability brought about by time, behaviour, heterogeneity and a combination of the three (Otis et al., 1978). For each occasion, parameter estimates were generated under a model that best fit the data (see Otis et al., 1978). In this case, parameter estimates were generated under the assumptions of model $\mathrm{M}_{\mathrm{h}}$, which was the best-fit model for the analysis. We used the jackknife estimator to estimate leopard capture probabilities $(P)$ and population size $(N)$.

To identify the effort at which the values and precision of population estimates stabilized, we recalculated estimates for each simulation and plotted values and precision against effort. Desirable precision of estimates was achieved when the variance was consistently less than $10 \%$ with increasing effort.

For each level of effort, we calculated abundance to generate a time series of increased survey effort. We then calculated the coefficient of variance (CV) in abundance indices at each increasing measure of effort. Similarly, we used the generalized accumulation curve and defined the desirable effort to estimate the abundance when the CV changed by less than $10 \%$ with increasing effort (Flather, 1996).

\section{Results}

\section{Population closure}

Population closure test yielded a $z$-score of -3.28 $(P<0.05)$. Despite the population closure test suggesting 
possible lack of closure, we used closed population models because (i) the cameras were left to run within the acceptable time period to assume closure (Karanth \& Nichols, 1998; Henschel \& Ray, 2003; Wang \& Macdonald, 2009); (ii) closed models are more robust than open models (Karanth \& Nichols, 2000); and (iii) deviation from population closure was marginal (Karanth et al., 2006).

\section{Defining how individual trapping success varied with time}

The 586 trap day effort yielded 24 leopard images of 14 individual adult leopards (eleven males and three females), resulting in a capture rate of 24.4 trap days per adult leopard capture. Of the fourteen individuals, five were re-captures. One individual was captured five times, while two were captured three times and two twice (Fig. 2a).
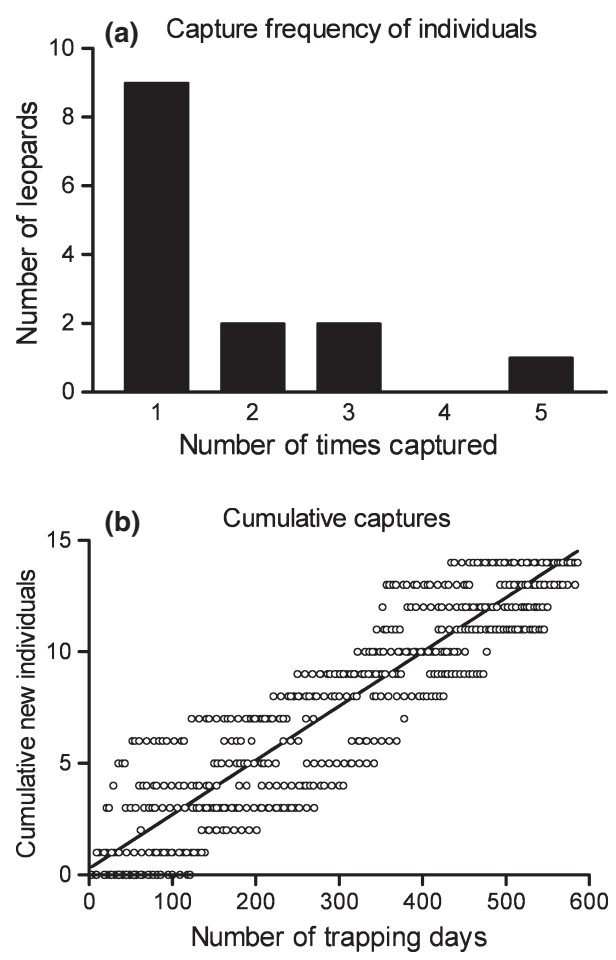

Fig 2 (a) Camera capture frequencies for leopards in the N'wanetsi concession, Kruger National Park, South Africa, during the period between April and August 2008. (b) Cumulative number of individual leopards with increasing effort following camera capture simulations (100 iterations)
Achieving an asymptote in new leopard individuals captured

Cumulative number of captures increased with effort. New leopard individuals continued to be encountered as the number of trapping days increased (Fig. 2b). Mean number of leopards observed Lobs (Mao Tau) was 14 (95\% CI $=8.88-19.12$ ) (Fig. 3). An asymptote was not reached with regards to the values we would obtain for an infinite number of randomizations following Mao Chang Xuan including the upper and lower confidence intervals. An asymptote also was not reached for jackknife and bootstrap estimators, ACE and ICE (Fig. 3). The fitted MM continued to increase, albeit negligibly, with the increasing number of new captures (Fig. 3).

Effort at which precision of population estimates began to stabilize

Population estimates stabilized after 500 trap days (Fig. 4a). At 378 trap days, the precision of population estimates began to stabilize (Fig. 4b). Accuracy of population estimates was validated by visual presentation of stabilization of standard error with increasing effort (Fig. 4c). In the final 208 trap days and 47 trapping occasions, the variance recorded scores of $<1.00$ on average, a marked change from the variance scores of $\geq$ 20 in 23 occasions at the beginning of the survey (Fig. 4b). After 88 occasions, the probability of leopard capture was estimated at 0.013 , and the population was estimated at nineteen individuals $(\mathrm{SE}=4.55 ; 95 \%$ $\mathrm{CI}=15-35)$.

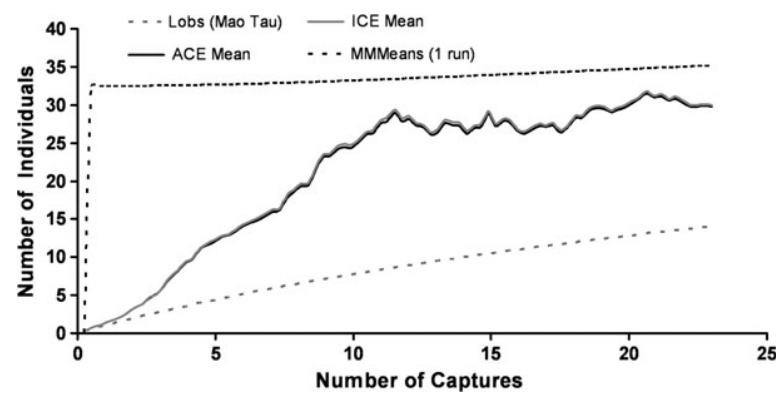

Fig 3 Estimates results for accumulation curves with abundance estimators, namely: leopards observed (Lobs), abundance-based coverage estimator (ACE), incidence-based coverage estimator (ICE) and the Michaelis-Menten mean estimator (MMMeans) for leopards in the N'wanetsi concession, Kruger National Park, South Africa during the period between April and August 2008 

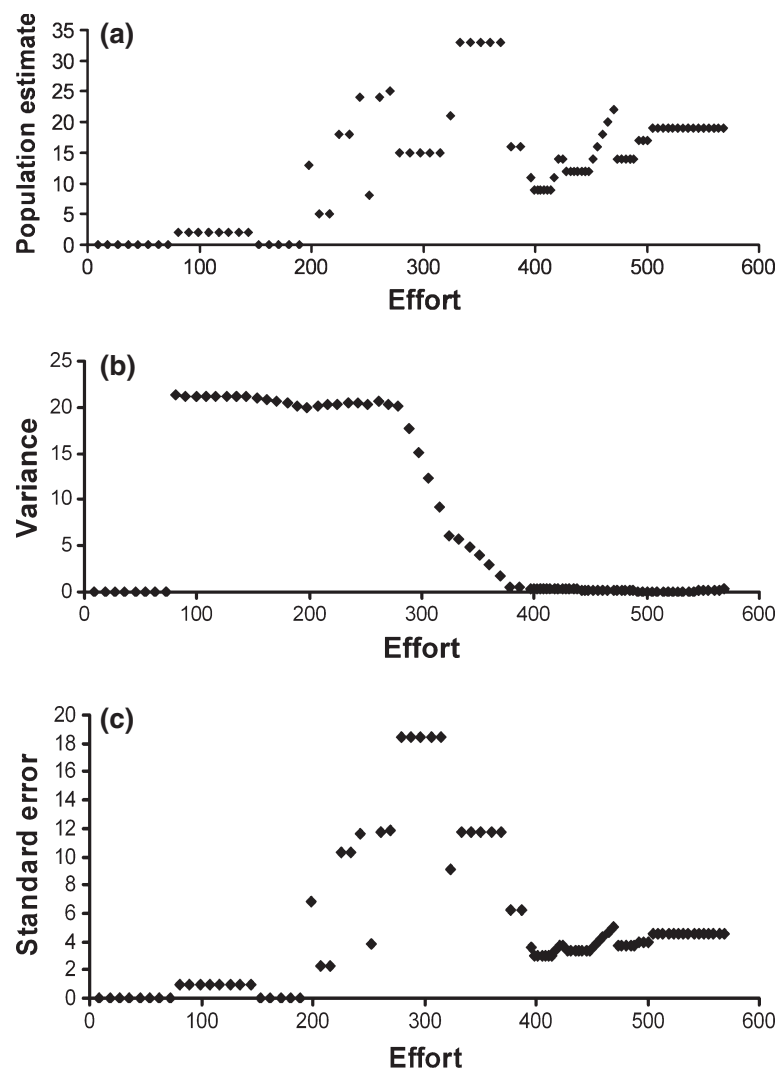

Fig 4 (a) Changes in leopard population estimates at the N'wanetsi concession of the Kruger National Park, South Africa, with increasing effort. (b) A plot depicting variance in population estimates for the leopards with increasing effort. (c) Standard error plotted against effort from the leopard camera surveys

\section{Discussion}

Attempts to validate robust leopard population estimates in South Africa's KNP have been minimal (but see Bailey, 1993), due to several challenges including resources and time needed for such a study. A lack of standardized methods to conduct leopard population surveys further exacerbated the challenge. In our study, we focused on addressing these shortcomings. Leopards are secretive and solitary (Skinner \& Chimimba, 2005) and use a variety of landscapes (Bothma \& Bothma, 2006). Both these factors may induce the variance in the effort needed to obtain robust population estimates. Our results suggest that $\sim 500$ trap days are required to achieve the stabilization of population estimates and precision thereof. This requirement is in accordance with that noted by Wang \& Macdonald (2009).
We noted two potential anomalies. First, the number of new individual leopards added to the population did not stabilize with increasing effort (Fig. 3). Individual accumulation curves showed little sign of reaching an asymptote with increasing number of leopards being captured. After 20 leopards captured, the number of unique leopards continued to increase. Similarly, bootstrap and jackknife estimate means did not show signs of levelling out, suggesting that we would continue to capture new individuals with increasing effort. In contrast, abundance estimators, particularly ACE and ICE, were not as sensitive and fluctuated after ten captures. The Michaelis-Menten mean estimator reached an asymptote at approximately 33 captured leopards although there was a subtle indication that it increased as more individuals captured. While this estimator rises rapidly, raising questions about its biological plausibility in this context, it gives an indication of where to likely capture all the individual leopards in the study area.

A second anomaly associated with population structure, and make-up also arose. We captured more males than females at a ratio of $4: 1$, a marked disparity in captures. This is surprising given that leopards in savannah ecosystems have been reported to have average home ranges of $\sim 16 \mathrm{~km}^{2}$ (Skinner \& Chimimba, 2005). In addition, males generally occupy territories overlapping two to four female territories (Bailey, 1993). Unlike lions where sexual dimorphism is distinct, in leopards, especially between males of approximately two years of age, it may not always be possible to differentiate the sexes (Balme, Hunter \& Braczkowski, 2012). After re-examining leopard images for the verification according to the recommendations by Balme, Hunter \& Braczkowski (2012), we found our assessment to be correct. Despite this, based on the current knowledge of leopard behaviour and ecology, we should have recorded more females than males. Krebs (1989) reviewed the possible causes of unequal catchability, namely: (i) behaviour in the vicinity of the trap; (ii) learning by animals from the ones that had already caught; and (iii) trap positions. Learning from other animals may not be applicable to adult leopards, but behaviour and trap position may have played a role in our study. Given that two of the females known to the guides at the time of the survey were not captured, several factors may contribute to this anomaly including: (i) the sampling design being heavily biased towards male preferred paths; (ii) females not being well-represented, suggesting that the study population is different from other studied leopard 
populations; (iii) there are hidden factors that may be contributing negatively to females; (iv) the cameras were set too far apart outside the females' home ranges; and (v) the males that we captured were dispersing individuals. Similar findings were reported for cheetahs (Marnewick, Bothma \& Verdoon, 2006; Marnewick, Funston \& Karanth, 2008; Chapman \& Balme, 2010), and (vi) the present data may be representative of a population in transition from one state to another.

A study on the response of tigers to camera traps found that some animals had a tendency to avoid camera stations, especially after the first exposure to the camera (Wegge, Pokheral \& Jnawali, 2004). This camera shyness may have been a factor in our study including the noncapture of the two known females in the area. However, we expected the leopards to have been exposed at least once before actively avoiding cameras. Nonetheless, we anticipated variability in individual capture probabilities because the model also may account for differences in home ranges, land use patterns and social hierarchy (Otis et al., 1978). This was confirmed when model $\mathrm{M}_{\mathrm{h}}$ was consistently selected as the best fit during simulations.

We did not use baits and lures in the present study because we anticipated model $\mathrm{M}_{\mathrm{h}}$, which accommodates differential capture probabilities (Otis et al., 1978; White et al., 1978). Baits and lures may homogenize capture probabilities (Thorn et al., 2009), but their application carries trade-offs. Camera traps need to be serviced more often to ensure bait and lures are still attractive. It is, however, acknowledged that using attractants during the survey could slow down target species, thus improving the quality of the image (Funston, P.J. Pers. comm.). Improvement of capture probabilities has been tested for brown hyaenas, Hyaena brunnea (Thorn et al., 2009). Small mammal capture studies typically use bait (Ferreira \& Van Aarde, 2000), and in associated markrecapture studies, models favouring heterogeneity in individual capture probabilities provide best fit to the observed data (Wang \& Macdonald, 2009). Studies using lures from other species had similar results (Quy et al., 2008). We thus anticipate that bait and lures are not likely to homogenize leopard capture probabilities and are, therefore, unlikely to result in selection of less complex capture models when estimating population sizes and variance in our study.

Our study suggests that there are 15-35 leopard individuals (nineteen being the likely estimate) in a $150 \mathrm{~km}^{2}$ area of the N'wanetsi concession. That translates to a density of 12.7 leopards per $100 \mathrm{~km}^{2}$, within the range of densities noted for several studies across South Africa in areas of comparable prey densities (Chapman \& Balme, 2010). The biased sampling by camera traps of leopards at the N'wanetsi concession has highlighted that (i) even with increased effort, we would continue to encounter new individuals; (ii) stabilization of population estimates should be anticipated at $~ 500$ trap days; and (iii) precision of population estimate should stabilize after $\sim 380$ trap days.

Successfully using camera traps to estimate leopard population abundance in the study area provides standard steps to follow in order to successfully survey the 2.2 million hectare KNP for leopards. We acknowledge that given the magnitude of the KNP, there are different landscapes, vegetation types, precipitation, soil types and prey densities. We expect that regardless of these causes of variation, there should be game paths, drainage lines and other common features that resemble the pilot study area used in the present study. The study also provides baseline data for leopards in the N'wanetsi section of the KNP, and future monitoring efforts can be used against this established benchmark.

\section{Acknowledgements}

We thank the South African National Parks for granting us permission to carry out this work. We are thankful to the Singita Group of the N'wanetsi concession in the KNP and their staff for support. We thank the KCS Pacific Foundation, The Nancy-Carroll Draper Foundation, and WESSA for funding this work. We thank Simon Munthali and Susan Shane for their valuable comments on the manuscript. We thank the anonymous reviewers, for making constructive comments on the manuscript.

\section{References}

AEBIscher, N.J. (1986) Estimating the proportion on uncatchable animals in a population by double-sampling. Biometrics 42 , 973-979.

Agresti, A. (1994) Simple capture-recapture models permitting unequal catchability and variable sampling effort. Biometrics 50, 494-500.

BAILEY, T.N. (1993) The African Leopard. Ecology and Behavior of a Solitary Felid. Columbia University Press, New York.

Balme, G.A., Hunter, L. \& Braczkowski, A.R. (2012) Applicability of age-based hunting regulations for African leopards. PLoS ONE 7, e35209.

Balme, G.A., Hunter, L.T.B. \& Slotow, R. (2009) Evaluating methods for counting cryptic carnivores. J. Wildl. Manag. 73, 431-443. 
Balme, G.A., Slotow, R. \& Hunter, L.T.B. (2010a) Edge effects and the impact of non-protected areas in carnivore conservation: leopards in the Phinda-Mkhuze Complex, South Africa. Anim. Conserv. 13, 315-323.

Balme, G.A., Hunter, L.T.B., Goodman, P., Ferguson, J.C., Craigie, J. \& SLOTOW, R. (2010b). An adaptive management approach to trophy hunting of leopards (Panthera pardus): a case study from KwaZulu-Natal, South Africa. In Biology and Conservation of Wild Felids (Eds. D. W. Macdonald and A. Loveridge). Oxford University Press, Oxford

Carbone, C. \& Gittleman, J.L. (2002) A common rule for scaling carnivore density. Science 295, 2273-2276.

Chapman, S. \& Balme, G. (2010) An estimate of leopard population density in a private reserve in KwaZulu-Natal, South Africa, using camera-traps and capture-recapture models. S. Afr. J. Wildl. Res. 40, 114-120.

Chazdon, R.L., Colwell, R.K., Denslow, J.S. \& Guariguata, M.R. (1998). Statistical methods for estimating species richness of woody regeneration in primary and secondary rainforests of NE Costa Rica. In: Forest Biodiversity Research, Monitoring and Modelling: Conceptual Background and Old World Case Studies (Eds F. DALLMEIER and J. A. COMISKEY). Parthenon Publishing, Paris.

Colwell, R.K. (2006). EstimateS: Statistical estimation of species richness and shared species from samples. Version 8.2.0. User's guide and application. Available at: http://purl.oclc.org/ estimates (accessed on December 2 2011).

Colwell, R.K. \& Coddington, J.A. (1994) Estimating terrestrial biodiversity through extrapolation. Philos. Trans. R. Soc. $\mathbf{3 4 5}$, 101-118.

Daly, B., Power, J., Camacho, G., Traylor-Holzer, K., Barber, S., Catterall, S., Fletcher, P., Martisns, Q., Martins, N., Owen, C., Thal, T. \& Friedmann, Y. (2005). Leopard (Panthera pardus) population and habitat viability assessment. In: Proceedings of a Workshop of the Conservation Breeding Specialist Group (World Conservation Union (IUCN) Species Survival Commission). Endangered Wildlife Trust, Johannesburg.

Bотнма, J. Du P. \& Bотнма, M.D. (2006) Activity patterns in southern Kalahari leopards. Afr. Zool. 41, 150-152.

Efford, M.G., Dawson, D.K. \& Robbins, C.S. (2004) Density: software for analysing capture-recapture data from passive detector arrays. Anim. Biodivers. Conserv. 27, 217-228.

FERreirA, S.M. \& Funston, P.J. (2010) Estimating lion population variables: Prey and disease effects in the Kruger National Park, South Africa. Wildl. Res. 37, 1-13.

FERREIRA, S.M. \& VAN AARDE, R.J.(2000). Maintaining biodiversity through intermediate disturbances: evidence from rodents colonizing rehabilitating coastal dunes. Afr.J.Ecol, 38, 286-294.

FLATHER, C.H. (1996) Fitting species-accumulation functions and assessing regional land use impacts on avian diversity. J. Biodiv. 23, 155-68.

GERTENBACH, W.P.D. (1980) Rainfall patterns in the Kruger National Park. Koedoe 23, 35-43.
GerTenBach, W.P.D. (1983) Landscapes of the Kruger National Park. Koedoe 26, 9-121.

HARRIs, R.B. (1986) Reliability of trend lines obtained from variable counts. J. Wildl. Manag. 50, 165-171.

Henschel, P. \& Ray, J. (2003) Leopards in African Rainforests: Survey and Monitoring Techniques. Wildlife Conservation Society, Global Carnivore Program, Available at: http://www. panthera.org/sites/default/files/LeopardManual_English_ lowres.pdf (accessed on December 13 2012).

Jackson, R.M., Roe, J.D., Wangchuk, R. \& Hunter, D.O. (2006) Estimating snow leopard population abundance using photography and capture recapture techniques. Wildl. Soc. Bull. 34, 772-781.

KARANTH, K.U. \& Nichols, J.D. (1998) Estimation of tiger densities in India using photographic captures and recaptures. Ecology 79, 2852-2861.

Karanth, K.U. \& Nichols, J.D. (2000) Monitoring Tigers and Their Prey: A Manual for Researchers, Managers and Conservationists in Tropical Asia. Centre for Wildlife studies, Karnataka, India.

KARANTH, K.U. \& Sunouist, M.E. (1995) Prey selection by tiger, leopard and dhole in tropical forests. J. Anim. Ecol. 64, 439-450.

Karanth, K.U., Nichols, J.D., Kumar, N.S. \& Hines, J.E (2006) Assessing tiger population dynamics using photographic capture-recapture sampling. Ecology 87, 2925-2937.

Kauffmann, M.J., Sanjayan, M., Lowenstein, J., Nelson, A., Jeo, R. M. \& CRooks, K.R. (1997) Remote camera-trap methods and analyses reveal impacts of rangeland management on Namibian carnivore communities. Oryx. 41, 70-78.

Kelly, M.J. (2008) Design, evaluate, refine: camera trap studies for elusive species. Anim. Conserv. 11, 182-184.

KÉRY, M. \& SCHMIDT, H. (2003) Monitoring programs need to take into account imperfect species detectability. Basic Appl. Ecol. 5, 65-73.

KREBS, C.J. (1989) Ecological Methodology. HarperCollins Publishers, New York.

LeE, S.-M. \& CHAo, A. (1994) Estimating population size via sample size coverage for closed capture-recapture models. Biometrics 50, 88-97.

Maffei, L., CuÉllar, E. \& Noss, A. (2004) One thousand jaguars (Panthera onca) in Bolivia's Chaco? Camera trapping in the KaaIya National Park. J. Zool. (Lond) 262, 295-304.

Marker, L.L., Mills, M.G.L. \& Macdonald, D.W. (2003) Factors influencing perceptions and tolerance toward cheetahs (Acinonyx jubatus) on Namibian farmlands. Conserv. Biol. 17, 1-9.

Marnewick, K., Bothma J. Du P. \& Verdoon, G.H. (2006) Using camera-trapping to investigate the use of a tree as a scentmarking post by cheetahs in the Thabazimbi district. S. Afr. J. Wildl. Res. 36, 139-145.

Marnewick, K., Funston, P.J. \& Karanth, K.U. (2008) Evaluating camera trapping as a method for estimating cheetah abundance in ranching areas. S. Afr. J. Wildl. Res. 38, 59-65.

Mills, M.G.L., Juritz, J.M. \& Zucchini, W. (2001) Estimating the size of spotted hyena (Crocuta crocuta) population through 
playback recordings allowing for non-response. Anim. Conserv. 4, 335-343.

NichoLs, J.D. (1992) Capture-Recapture Models. Bioscience 42, 94-102.

Otis, D.L., Burnham, K.P., White, G.C. \& Underson, D.R. (1978) Statistical inference from capture data on closed animal populations. Wildl. Monogr. 62, 3-135.

Ott, T., Kerley, G.I.H. \& Boshoff, A.F. (2006) Preliminary observations on the diet of leopards (Panthera pardus) from a conservation area and adjacent rangelands in the Baviaanskloof region, South Africa. Afr. Zool. 42, 31-37.

Owen-Smith, N. \& Mills, M.G.L. (2008) Predator-prey size relationships in an African large-mammal food web. J. Anim. Ecol. 77, 173-183.

Quy, R.J., Watkins, R.W., LAmberT, M.S. \& CoWAN, D.P. (2008) Validating census methods to measure changes in house mouse populations. Pest Manag. Sci. 65, 275-282.

ReXtAD, E. \& Burnham, K.P. (1991) User's Guide for Interactive Program CAPTURE. Fort Collins, CO, Colorado Cooperative Fish and Wildlife Unit.

Romero-Muñoz, A., Maffei, L., Cuéllar, E. \& Noss, A.J. (2010) Temporal separation between jaguar and puma in the dry forests of southern Bolivia. J. Trop. Ecol. 26, 303-311.

Rowcliffe, J.M., Field, J., Turvey, S.T. \& CArbone, C. (2008) Estimating animal density using camera traps without the need for individual recognition. J. App. Ecol. 45, 1228-1236.

Sharma, K.R. \& JHALA, Y.V. (2011) Monitoring tiger populations using intensive search in a capture-recapture framework. Popul. Ecol. 53, 373-381.

Skinner, J.D. \& ChImimbA, C.T. (2005) The Mammals of the Southern African Subregion (3rd Ed). Cambridge University Press, Cambridge, UK.

Stein, A.B., Fuller, T.K. \& Marker, L.L. (2008) Opportunistic use of camera traps to assess habitat-specific mammal and bird diversity in northcentral Namibia. Biodivers. Conserv. 17, 3579-3587.

Stephens, P.A., Zaumyslova, O.YU., Miouelle, D.G., Myslenkov, A.I. \& HAYWARD, G.D. (2006). Estimating population density from indirect sign: track counts and the Formozov-MalyshevPereleshin formula. Anim. Conserv. 9, 339-348.

Thompson, W.L. (2002) Towards reliable bird surveys: Accounting for individuals present but not detected. Auk. 119, 18-25.

Thompson, G.G., Withers, P.C., Pianka, E.R. \& Thompson, S.A. (2003) Assessing biodiversity with species accumulation curves; inventories of small reptiles by pit-trapping in Western Australia. Austral Ecol. 28, 361-383.

Thorn, M., ScotT, D.M., Green, M., Bateman, P.W. \& CAmeron, E.Z. (2009) Estimating brown hyaena occupancy using baited camera traps. S. Afr. J. Wildl. Res. 39, 1-10.

Tobler, M.W., Carrillo-Percastegui, S.E., Leite Pitman, R., Mares, R. \& PowelL, G. (2008). An evaluation of camera traps for inventorying large- and medium-sized terrestrial rainforest mammals. Anim. Conserv. 11, 169-178.

WANG, S.W. \& MACDONALD, D.W. (2009) The use of camera traps for estimating tiger and leopard populations in the high altitude mountains of Bhutan. Biol. Conserv. 142, 606-613.

Wegge, P., Pokheral, C.P. \& JNawali, S.R. (2004) Effects of trapping effort and trap shyness on estimates of tiger abundance from camera trap studies. Biol. Conserv. 7, 251-256.

White, G.C., Burnham, K.P, Otis, D.L. \& Anderson, D.R.(1978). User's Manual for Program CAPTURE. Utah State University Press, Logan, Utah

(Manuscript accepted 15 October 2012)

doi: 10.1111/aje.12047 